\title{
Avaliação neuropsicomotora e classificação funcional em escolares de 10 a 12 anos da rede pública
}

\section{Neuropsychomotor evaluation and functional classification in schoolchildren between the ages of 10 and 12 from the public school system}

\author{
Adriano Zanardi da Silva', Audrin Said Vojciechowski ${ }^{1}$, Tainá Ribas Mélo², Bruna \\ Yamaguchi $^{3}$, Alessandro Said Touchan ${ }^{4}$, Andréa Serio Bertoldi ${ }^{5}$, Vera Lúcia Israel ${ }^{6}$ \\ http://dx.doi.org/10.11606/issn.2238-6149.v27i1p52-62
}

Silva AZ, Vojciechowski AS, Mélo TR, Yamaguchi B, Touchan AS, Bertoldi AS, Israel VL. Avaliação neuropsicomotora e classificação funcional em escolares de 10 a 12 anos da rede pública. Rev Ter Ocup Univ São Paulo. 2016 jan.-abr.;27(1):52-62.

RESUMO: O desenvolvimento neuropsicomotor (DNPM) envolve as áreas motoras e cognitivas e é influenciado por questões do ambiente e da tarefa, o que numa visão ampliada de saúde pode ser classificado por meio da Classificação Internacional de Funcionalidade, Incapacidade e Saúde (CIF). O objetivo deste estudo foi avaliar o DNPM de escolares e classificá-los de acordo com a CIF. Participaram do estudo 22 pré-adolescentes (10 a 12 anos) de ambos os sexos, na região metropolitana de Curitiba, avaliados por meio da Bateria Psicomotora de Fonseca, Medida da independência funcional, entrevista semiestruturada $e$ check-list da CIF para crianças e jovens (CIF-CJ). Observou-se que a maioria dos estudantes não apresentou alterações no DNPM, e que o auto-relato identificou: mudança no modelo familiar, poucas possibilidades para esporte e lazer, preferência pelas brincadeiras como entretenimento, escola como ambiente predominante, boa autopercepção de saúde, dificuldade de acessibilidade. Além disso, identificou-se uma criança com atraso em fatores psicomotores isolados, mas com bom desempenho psicomotor geral. A utilização do modelo proposto pelos autores respondeu às dimensões da CIF, indicando sua aplicabilidade e possibilidades de uso em ambiente escolar.

DESCRITORES: Educação infantil; Saúde escolar; Desempenho psicomotor; Inclusão educacional; Classificação Internacional de Funcionalidade, Incapacidade e Saúde.
Silva AZ, Vojciechowski AS, Mélo TR, Yamaguchi B, Touchan AS, Bertoldi AS, Israel VL. Neuropsychomotor evaluation and functional classification in schoolchildren between the ages of 10 and 12 from the public school system. Rev Ter Ocup Univ São Paulo. 2016 Jan.-Apr.;27(1):52-62.

\begin{abstract}
Neuropsychomotor development (NPMD) involves the motor and cognitive areas and is influenced by environmental and task questions, which from an expanded health point of view can be classified by the International Classification of Functioning, Disability and Health (ICF). The objective of this study was to evaluate the school's NPMD and classify them according to the ICF. The study included 22 pre-adolescents (10-12 years) of both sexes, in the metropolitan region of Curitiba, Brazil, assessed by the Fonseca's Psychomotor Battery, the Functional Independence Measure, semi-structured interviews and ICF checklist for children and youth (ICF-CY). We observed that most students did not show changes in the NPMD, and that the selfreport identified: changes in the family model, few possibilities for sports and leisure, preference for playing as entertainment, school as the prevailing environment, good self-perception of health, accessibility problems. In addition, we identified one child with delay in some isolated psychomotor factors, but with a good general psychomotor performance. The use of the model proposed by the authors answered the demands of the ICF, indicating its applicability and possibilities of use in the school environment.
\end{abstract}

KEYWORDS: Child education; School health; Psychomotor performance; Mainstreaming (education); International Classification of Functioning, Disability and Health.

Este trabalho foi realizado na Disciplina da Saúde e Funcionalidade do Programa de Pós Graduação em Educação Física da UFPR.

1. Graduado/a em Fisioterapia pela Universidade Federal do Paraná (UFPR), Curitiba-PR, Brasil. Email: zanardiufpr@gmail.com/ asaidvoj@gmail.com

2. Fisioterapeuta, Doutoranda em Atividade Física e Saúde (UFPR), Docente da Universidade Campos Andrade (UNIANDRADE) e do Instituto Brasileiro de Terapias e Ensino (IBRATE), Curitiba, PR, Brasil. Docente e tutora do Curso de Especialização em Gênero e Diversidade na Escola - UFPR, Matinhos, PR, Brasil. Email: ribasmelo@gmail.com

3. Fisioterapeuta, Mestranda em Atividade Física e Saúde (UFPR), Curitiba, PR, Brasil. Email: brunayamaguchi@hotmail.com

4. Professor de Educação Física. Especialista em Docência no Ensino Superior (UNICESUMAR), Docente Titular do Quadro Próprio do Magistério da Rede Pública do (Estado do Paraná), São José dos Pinhais, PR, Brasil. Docente da Escola de Segurança (Hunter's), Curitiba, PR, Brasil. Email: aletouchan@hotmail.com

5. Doutora em Comportamento Motor pela Universidade Federal do Paraná (UFPR), Brasil. Professora Titular da Universidade Estadual do Paraná, Brasil. Email: seriobertoldi@gmail.com

6. Doutora em Educação Especial pela Universidade Federal de São Carlos (UFSCar), Brasil. Professora Adjunto da Universidade Federal do Paraná (UFPR) e do Programa de Pós Graduação em Educação Física da UFPR, Brasil. Email: veral.israel@gmail.com

Endereço para correspondência: Adriano Zanardi da Silva. Rua Coração de Maria, 92. Campus Jardim Botânico, Curitiba, PR, Brasil. CEP: 80210-132. Email: zanardiufpr@gmail.com 


\section{INTRODUÇÃO}

$\mathrm{O}$ desenvolvimento, na perspectiva ecológica, é um processo contínuo de aquisições neuropsicomotoras, cognitivas e afetivas, que ocorrem à medida em que a criança e/ou adolescente vivencia o ambiente físico e social ${ }^{1}$. Na adolescência, fase de desenvolvimento caracterizada pela transição física e psicológica que ocorre de forma não-linear, diversas são as definições quanto à faixa etária de abrangência, sendo algumas relacionadas à puberdade (maturação) e outras que consideram fatores diversos. Para a Organização Mundial da Saúde (OMS), são adolescentes aqueles têm de 10 a 19 anos, podendo também ser classificados como pré-adolescentes os que têm entre 10 e 14 anos $^{2}$. No Brasil, o Estatuto da Criança e do Adolescente (ECA) rege a idade 12 a 18 anos $^{3}$ como adolescência.

Entre 10 a 14 anos, os pré-adolescentes ${ }^{2}$, encontram-se na fase motora especializada, na qual utilizam suas aquisições para a melhora da performance motora, e por isso é esperado o desenvolvimento de suas habilidades psicomotoras básicas ${ }^{4}$ as quais servirão para o pleno desenvolvimento intelectual ${ }^{5}$, auxiliando nas aquisições escolares.

A atualização de conceitos de saúde traz novas demandas de avaliação relacionadas à saúde, as quais consideram as diferentes funções humanas em direta ligação com o ambiente, estilo de vida e das demandas das tarefas ${ }^{4,6}$ e devem, portanto, ser consideradas na avaliação de crianças e adolescentes ${ }^{7}$. Essa nova abordagem vai ao encontro do modelo proposto pela Classificação Internacional de Funcionalidade, Incapacidade e Saúde (CIF), que classifica os principais domínios de aspectos de saúde em relação às funções e estruturas do corpo, atividades e participação, considerando os fatores ambientais e pessoais. Os domínios relacionados às funções e estruturas do corpo classificam aspectos fisiológicos e anatômicos enquanto os relacionados às atividades e participação dizem respeito às demandas cotidianas de funcionalidade do indivíduo em vários aspectos da vida individual e social. Além disso, consideram-se questões ambientais e pessoais como fatores contextuais que influenciam os demais domínios 8 .

Avaliar a funcionalidade utilizando a CIF é um tema de interesse crescente, desenvolvida pela Organização Mundial da Saúde (OMS) como uma ferramenta para unificação da terminologia aplicada internacionalmente para a descrição da funcionalidade de indivíduos ${ }^{8,9}$. A versão da CIF para crianças e Jovens (CIF-CJ) é utilizada para avaliar crianças e adolescentes, a qual analisa os mesmos domínios relacionados à saúde abordados na CIF com algumas especificidades da infância à adolescência ${ }^{10,11}$ e que atualmente foi incorporada à nova versão da CIF9 .

Embora o atual modelo preconize a atenção à saúde e a CIF possa ser amplamente utilizada, observa-se que em termos de pesquisas, a maioria dos estudos que a utilizam a fazem em condições patológicas ${ }^{12}$, sendo necessárias investigações e descrições dos domínios da CIF também em condições de ausência de doenças. Para ser possível a classificação com a CIF e CIF-CJ é necessária à utilização prévia de instrumentos de medida qualitativos ou quantitativos.

Considerando o que foi exposto, o presente artigo teve como objetivo geral avaliar o desenvolvimento neuropsicomotor de escolares e classificá-los de acordo com a Classificação Internacional da Funcionalidade (CIF). Além disso, buscou-se identificar as condições contextuais de saúde de escolares pré-adolescentes e estimular a utilização da CIF nessa população.

\section{METODOLOGIA}

O presente estudo tem delineamento transversal de avaliação e classificação ${ }^{13}$, de caráter quali-quantitativo, que visa identificar as condições contextuais de saúde de pré-adolescentes que frequentam escola da rede pública. Inicialmente, foi realizado o contato com a direção escolar e, sendo concedida a autorização, o projeto foi submetido e aceito pelo Comitê de Ética em Pesquisa do HT, com aprovação parecer $\mathrm{n}^{\mathrm{o}}$ 1.373.189.

Como critérios de inclusão os participantes do estudo deveriam ser pré-adolescentes, com idade de 10 a 12 anos, de ambos os sexos, devidamente matriculados em uma escola estadual do município de São José dos Pinhais, na região metropolitana da capital do estado do Paraná. Os critérios de exclusão foram a não autorização dos responsáveis para a participação dos pré-adolescentes no estudo, a ausência no dia das avaliações ou a recusa de participação voluntaria no estudo. Foram avaliados 22 préadolescentes com média de $11,5( \pm 0,51)$ anos de idade, sendo 13 meninos $(59,1 \%)$ e 8 meninas $(40,9 \%)$, numa escola estadual de São José dos Pinhais.

Previamente às avaliações, foi realizada familiarização com o ambiente da escola e treinamento com os instrumentos de avaliação por cinco avaliadores (fisioterapeutas e professor de educação física).

As avaliações consistiram na aplicação de três instrumentos, escolhidos após análise dos principais domínios a serem classificados pela CIF-CJ: Bateria Psicomotora (BPM $)^{13}$; Medida de Independência 
Funcional (MIF) $)^{14}$; e a entrevista semiestruturada. O processo de avaliação completo levou cerca de 50 minutos. As avaliações (BPM e MIF) foram classificadas (CIF-CJ) com relação às estruturas e/ou funções, em atividades e participação, assim como apresentam um contexto geral de domínios de escolares de 10 a 12 anos.

Para organização das avaliações visando contemplar a CIF-CJ, os autores propuseram o modelo, esquematizado na Figura 1. Nesse modelo observase os instrumentos de avaliação citados (BPM, MIF e entrevistas) nas extremidades relacionando-se uns com os outros de forma a centrar a classificação pela CIFCJ. Tal proposta de avaliações e classificação pode ser utilizada por todos os profissionais da reabilitação (terapeutas ocupacionais, fisioterapeutas, psicólogos, fonoaudiólogos, etc).

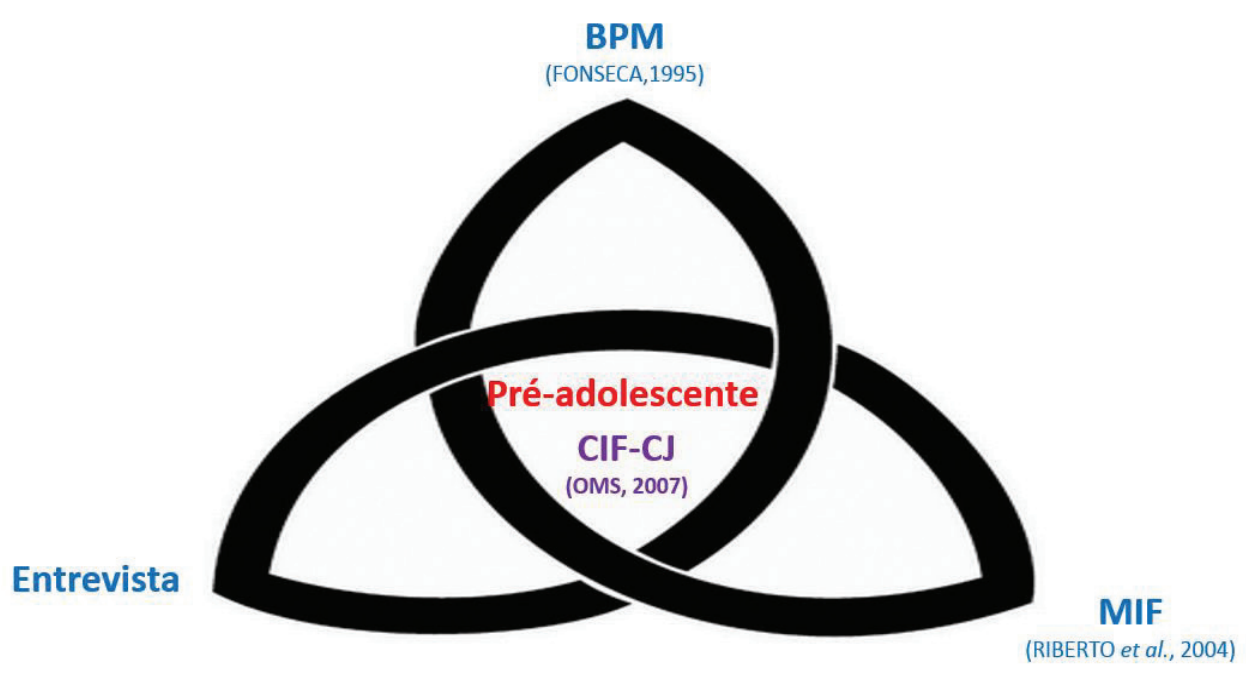

Fonte: Os autores

Figura 1 - Metodologia de avaliação e classificação proposta pelos autores

\section{Avaliação pela Bateria Psicomotora de Fonseca (BPM)}

A $\mathrm{BPM}^{14}$ abrange as áreas psicomotoras de tônus, equilíbrio, lateralidade, noção do corpo, organização espaço-temporal, praxia global, praxia fina, organizadas numa bateria de testes, foi aplicada e pontuada por observação direta. Segundo Fonseca ${ }^{14}$ cada fator recebe pontuação de 1 a 4, sendo 1 referente ao perfil apráxico, 2 ao dispráxico, 3 ao eupráxico e 4 ao hiperpráxico. Com os 7 fatores é possível obter um perfil geral, pela soma dos fatores pontuados: deficitário ( 7 a 8 pontos), dispráxico ( 9 a 13 pontos), normal (14 a 21 pontos), bom (22 a 26 pontos) ou superior (27 a 28 pontos).

\section{Medida de Independência Funcional X CIF-CJ}

A Medida da independência funcional (MIF) ${ }^{15}$ foi aplicada para verificar as Atividades de Vida Diária (AVDs), autocuidado, mobilidade, comunicação e cognição social e controle de esfíncteres. Cada atividade é avaliada e recebe uma pontuação que parte de 1 (dependência total) a 7 (independência completa), assim a pontuação total varia de 18 a 126. A MIF foi pontuada de forma indireta, ou seja, por questionamento aos participantes.

\section{Entrevista Semi-estruturada X CIF-CJ}

Por fim, foi realizada a entrevista semi-estruturada, sobre condições de saúde, escola e outras atividades, participação, relação interpessoal e dificuldades que podem estar relacionadas a estes domínios da vida (Apêndice 1).

\section{CIF-CJ}

A CIF apresenta-se dividida em quatro domínios: funções do corpo, estruturas do corpo, atividades e participação e fatores ambientais ${ }^{8,9}$. A expressão Funções do corpo relaciona-se às funções fisiológicas, a expressão 
Estruturas do corpo relaciona-se às partes anatômicas do organismo, e Atividades e Participações indicam o envolvimento dos indivíduos em ações e situações da vida cotidiana. Os Fatores de contexto são divididos em Fatores Ambientais e Fatores Pessoais. Os fatores pessoais não apresentam codificação e são utilizados de forma descritiva ${ }^{8,9}$. A definição da funcionalidade inclui a presença de um qualificador (que funciona com uma escala genérica de 0 a 4 , onde 0 é nenhuma deficiência e 4 uma deficiência completa). $\mathrm{O}$ valor 8 é utilizado em situações não especificadas e o 9 quando não aplicável. Os qualificadores validam a magnitude da deficiência, limitação, restrição, barreiras ou facilitadores das condições de saúde ${ }^{9}$. Embora a classificação pela CIF-CJ tenha sido realizada após as avaliações, a mesma guiou a escolha desses instrumentos e indicou qual domínio específico da CIF-CJ seria contemplado pelas avaliações (Figura 2).

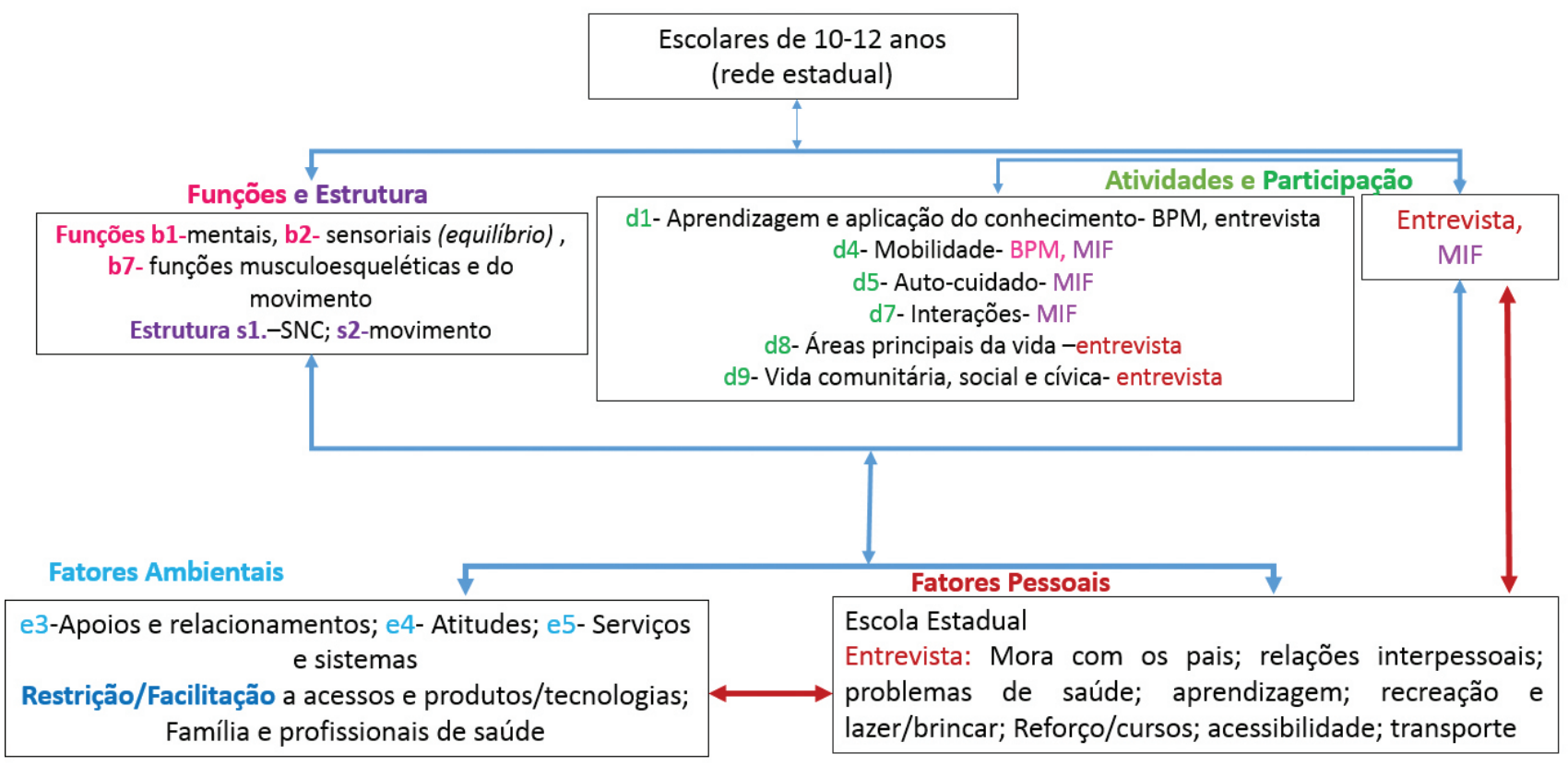

Figura 2 - Organização das avaliações pelo modelo da CIF-CJ ${ }^{9,10}, \mathrm{BPM}^{14}$ e $\mathrm{MIF}^{15}$

\section{ANÁLISE DOS DADOS}

As variáveis nominais e/ou ordinais foram descritas em frequência absoluta e percentual, já as variáveis numéricas foram descritas em média e desvio padrão, utilizando estatística descritiva realizada no programa Microsoft Excel ${ }^{\circledR}$ 2013. Com relação aos resultados do questionário semiestruturados, a análise foi organizada por temas centrais emergentes ${ }^{16}$, após leitura e organização das respostas.

\section{RESULTADOS}

\section{Avaliação pela Bateria Psicomotora de Fonseca X CIF-CJ}

Os principais resultados com relação aos fatores psicomotores avaliados pela $\mathrm{BPM}^{14}$ são apresentados na Tabela 1.
Não foram identificadas alterações nas funções e estruturas relacionadas aos aspectos psicomotores para a maioria das crianças avaliadas $(95,45 \%)$, sendo a maioria das crianças $(72,73 \%$ e $22,73 \%)$ com perfis eupráxico e hiperpráxico, respectivamente, na média dos fatores avaliados. Como pontuação total da BPM a média dos alunos avaliados foi de $24( \pm 0,26)$ pontos, o que é classificado pela BPM como um perfil psicomotor "Bom". Dessas crianças $13(61,90 \%)$ apresentam tipo físico mesomorfo, $3(14,29 \%)$ perfil endomorfo e $6(28,57 \%)$ perfil ectomorfo.

\section{Medida de Independência Funcional X CIF-CJ}

Pela MIF percebe-se (Tabela 2) independência total nas AVD's em atividades que competem serem independentes para $95,45 \%$ das crianças avaliadas. 
Silva AZ, et al. Avaliação neuropsicomotora e classificação funcional em escolares. Rev Ter Ocup Univ São Paulo. 2016 jan./abr.;27(1):52-62.

Tabela 1 - Resultados Quali-Quantitativos das avaliações pela BPM

\begin{tabular}{l|c|c|c}
\hline BPM (n=22) & Pontuação média & & \\
\hline I- Tonicidade (T) & 4 & & \\
\hline II- Equilibração (E) & 3 & & \\
\hline III-Lateralização (L) & 3 & & \\
\hline IV-Noção do corpo (NC) & 3 & & \\
\hline V-Estruturação espaço temporal (EET) & 3 & & \\
\hline VI-Praxia global (PG) & 4 & & \\
\hline VII-Praxia fina (PF) & 24 & $72,73 \%$ & Eupráxico \\
\hline Soma & 3 & $22,73 \%$ & Hiperpráxico \\
\hline Média & 0,26 & $4,55 \%$ & Dispráxico \\
\hline Desvio Padrão & 4 & \\
\hline
\end{tabular}

4: hiperpráxico; 3: eupráxico; 2: dispráxico; 1: apráxico

Tabela 2 - Avaliação da Medida de Independência Funcional (MIF)

\begin{tabular}{c|c|l}
\hline $\mathbf{n = 2 2}$ & MIF & \\
\hline 21 & $95,45 \%$ & Indep. Completa (todos os itens) \\
\hline 1 & $4,55 \%$ & $\begin{array}{l}\text { Ajuda mínima/ Indep. Modificada (Auto-cuidado: alimentação; Cognição Social: resolução de problemas e } \\
\text { memória). }\end{array}$ \\
\hline
\end{tabular}

Apenas 1 aluno (4,55\%) na idade mencionada apresentou domínios de desempenho inferiores a seus pares e trata-se de um aluno incluído classificado como deficiência intelectual (alteração da estrutura s110.8, e função não especificado b160.8, b164.8, b172.8), sem alterações de tônus, força muscular e/sou sinais de alterações de reflexos na avaliação física. Esse aluno apresentou tonicidade, lateralização, noção do corpo e praxia global com perfil eupráxico e, portanto, sem alterações. Nos domínios relacionados à equilibração, estruturação-espaço temporal e praxia fina a criança apresentou perfil dispráxico sendo classificada como alteração leve pela CIF-CJ (b.147.1) nesses domínios. Pode-se então dizer que a deficiência intelectual interfere nas suas habilidades motoras e nos domínios mencionados.

Isso também fora evidenciado por algumas pontuações da MIF que indicam uma supervisão do cuidador no cumprimento de AVD's nas áreas de auto-cuidado (alimentação), comunicação (compreensão) e cognição social (resolução de problemas e memória). Assim, essa criança apresenta alteração leve de aprendizagem e aplicação do conhecimento (b117.1, e d1.1), autocuidado (d5.1), muito embora apesar dessas características encontre-se em escola regular e sala comum, com reforço propiciado pelo Atendimento Educacional Especializado
(AEE), o que lhe confere inclusão e facilita suas atividades e participação (e3+4, e5+4). Portanto a sala de AEE foi considerado um facilitador desse processo de inclusão.

\section{Entrevista Semi-estruturada X CIF-CJ}

De maneira geral, os pré-adolescentes não apresentam restrições nos domínios de aprendizagem e aplicação do conhecimento, mobilidade, auto-cuidado quando investigadas suas atividades, no entanto, com relação à participação e fatores ambientais algumas crianças relatam não ter acesso a outras formas de educação (cursos) e que as questões ambientais de falta de acessibilidade são percebidas pelas mesmas no entorno da escola e de suas casas. Esses itens foram possíveis de serem identificados por meio das entrevistas.

Quanto às relações interpessoais, relacionadas à família e moradia, 6 alunos relatam não morar com o pai e a mãe, sendo que 2 citaram a presença de padrastos e 4 com apenas a presença da mãe; 7 adolescentes não têm irmãos. Nas relações interpessoais com amigos, 5 alunos relatam ter dificuldades com amizades e destes 2 admitem já ter ocorrido agressão física nos desentendimentos com colegas.

Em relação à saúde, 8 estudantes dizem ter problemas: sendo 2 relatos de bronquite e os demais de asma, convulsão, rinite + labirintite, rinite, déficit visual 
+ dor de cabeça, sopro cardíaco não confirmado. Desses apenas 3 (os que citaram ter da rinite + labirintite, asma e convulsão) relatam que essas condições têm repercussão sobre suas atividades diárias.

Quando questionados sobre sua aprendizagem, 6 alunos afirmam ter dificuldade. Todos os alunos se baseiam nas notas para afirmar se estão com dificuldades ou não na aprendizagem na escola. Neste contexto, um aluno relatou que já reprovou um ano, e que cursa novamente a série que não passou. Um aluno relata que deixou de estudar quando sua avó adoeceu com problemas de saúde relacionados a diabetes com amputação de membro. Um dos estudantes queixa-se de dificuldade para escrever. Um aluno frequenta reforço escolar e um dos estudantes ingressou na escola no segundo ano do ensino fundamental, não cursou o primeiro ano, pois a família o matriculou tardiamente.

Todos relatam que têm atividades de lazer e de recreação. As atividades relacionadas com religião, como missas e cultos, foram descritas por 5 estudantes. Futebol e brincadeiras de ruas foram lembradas por 4 adolescentes, outras atividades citadas foram posar fora de casa, jogar bola, vôlei ou basquete, passear e ir ao parque. As atividades mencionadas por apenas um aluno foram ver televisão, jogar no computador, usar tablet, ir à casa da avó, bicicleta, ping-pong, reunião de jovens e pescar.

Quanto a atividades extras (cursos, reforço, etc) além das aulas na escola, 6 estudantes contaram participar de outras atividades. As citadas foram 2 alunos no futebol e os demais citaram catequese, aula de guitarra, informática + inglês e reforço escolar.

Apenas 2 estudantes relatam que não brincam mais. As brincadeiras mais citadas, por preferência, foram: brincar na rua com colegas, de bola, futebol, bicicleta, patins, basquete, pega pega, bulica, esconder, corda e boneca.

Quanto à mobilidade e acesso, duas estudantes relataram ter dificuldades com a calçada próxima à escola, a qual se encontra em obras. Os demais não relatam dificuldades de acessibilidade dentro ou fora da escola. Quanto ao meio de transporte a família de 3 alunos optou por transporte para aula de van/ 3 chegam a aula com veículo dos pais (carro ou moto); 9 vão a pé à escola, sendo 5 acompanhados de adultos (com um relato de aluna só vai à escola quando não chove, porque quem a leva é um tio cadeirante), 2 sozinhos e 2 na companhia de colegas que estudam na mesma escola; 3 utilizam de bicicleta sozinhos e 1 de bicicleta acompanhado das irmãs que também estudam na mesma escola.

\section{DISCUSSÃO}

Com os instrumentos utilizados, foi possível observar os fatores contextuais da saúde dos préadolescentes, possibilitando a classificação da situação atual de saúde desta amostra.

Castanedal e Bahia $^{12}$ numa revisão sistemática sobre uso da CIF identificaram as pesquisas existentes somente em condições patológicas, sendo escassos estudos que descrevam a população típica, em especial crianças e adolescentes, o que ressalta a contribuição do presente estudo.

\section{Avaliação pela Bateria Psicomotora de Fonseca X CIF-CJ}

A maioria $(72,73 \%$ e $22,73 \%)$ das crianças do estudo, com 10 a 12 anos apresentaram perfis eupráxico e hiperpráxico respectivamente, com perfil geral classificado como "Bom" o que segundo Campos et al. ${ }^{17}$ é o esperado para essa faixa etária. Isso porque essa idade configura fase de especialização dos movimentos, onde se espera que estejam mais maduros e coordenados. Os estímulos ambientais fornecidos pela família e pelo próprio ambiente, favorecem a especialização morfo-químico-funcional das células do sistema nervoso, com formação de sinapses entre estruturas funcionais do sistema nervoso, que são quantitativamente mais intensas quanto mais estimuladas ${ }^{18}$.

$\mathrm{O}$ fato de um dos pré-adolescentes avaliados apresentar perfil dispráxico explicita bem a relação existente entre intelecto e motricidade, isso porque é um aluno incluído com deficiência intelectual (DI) sem outras deficiências associadas, e que apresentou desempenho inferior aos seus pares, especialmente nos fatores equilibração, estruturação espaço-temporal e praxia fina. Torna-se evidente que o SNC é plástico e com várias possibilidades de reorganização com adaptabilidade funcional possibilitadas por uma retroalimentação constate do ambiente ${ }^{19}$. Logo, vale destacar que quanto mais precoces são as avaliações, maiores são as chances de evitar que distúrbios e déficits neuropsicomotores afetem o desenvolvimento e desempenho (pessoal, profissional e acadêmico) das crianças e adolescentes ${ }^{20}$.

Embora tenham sido evidenciadas alterações psicomotoras em fatores isolados, no seu perfil geral apresenta classificação "normal". Isso leva a pensar nos efeitos positivos da inclusão, como um facilitador ambiental que, mais que "normalizar" funções e estruturas, permite o desenvolvimento dos fatores psicomotores. Assim sendo, Campos et al. ${ }^{17}$ citam que identificar fatores deficitários e potenciais na avaliação do perfil psicomotor favorece traçar 
diretrizes de intervenção direcionadas à população em questão, seja para fins de promoção, prevenção, reeducação do desenvolvimento no ambiente escolar.

Essas alterações psicomotoras encontradas são decorrentes de alteração da estrutura (s110.8), e das funções (b160.8, b164.8, b172.8) relacionadas ao SNC classificadas como não especificadas devido a inexistência de exames que evidenciem a natureza ou tipo de alteração. O escolar apresenta alterações nas 3 unidades funcionais propostas por Fonseca ${ }^{14,21}$. Isso porque a medula espinhal, tronco encefálico, tálamo, hipotálamo e o cerebelo, constituem a primeira unidade funcional e são responsáveis pela regulação da tonicidade e equilibração. A segunda unidade funcional, composta pelas áreas corticais dos lobos occipital, temporal e parietal, relaciona-se com os fatores psicomotores de lateralização, noção do corpo e estruturação espaço-temporal. Por fim, a terceira unidade funcional, que envolve o córtex do lobo frontal, é responsável pela praxia global e fina ${ }^{22}$ e foram evidenciadas alterações psicomotoras relacionadas a todas essas unidades pela BPM assim como nos domínios da CIF-CJ. Assim, entende-se que embora existam alterações nos fatores de equilibração, estruturação espaço-temporal e praxia fina, nos quais o escolar com DI apresentou desempenho inferior aos seus pares, essas são passíveis de estímulos em ambiente escolar ${ }^{23}$.

\section{Medida de Independência Funcional X CIF-CJ}

Observa-se correlação da deficiência intelectual nos componentes avaliados que apresentaram alterações e que são mencionados por Bezerra e Araújo ${ }^{24}$ principalmente na questão de transferências de aprendizagens.

Dentre os participantes deste estudo, apenas um escolar não apresentou o escore "independência completa" em todos os itens da MIF. Assim, este aluno com DI, apesar de desempenho intelectual inferior à média com limitações adaptativas, para Moura et al. ${ }^{25}$ podem haver achados nesta faixa etária onde o pré-adolescente típico ainda não é completamente independente.

\section{Entrevista Semiestruturada X CIF-CJ}

A escola é citada por Biasoli-Alves ${ }^{26}$ como espaço que deve proporcionar, na ausência de outras políticas públicas, a participação social, dando possibilidade de alcançar ao máximo as potencialidades do préadolescente. A qualidade dos estímulos ofertados pelas escolas influencia positivamente na saúde das crianças e adolescentes, já ambientes pobres nestes recursos, tem menor desempenho nas diversas áreas do desenvolvimento infantil ${ }^{27}$ e no presente estudo observa-se que de maneira geral os estímulos vivenciados pelas pré-adolescentes avaliados têm repercutido positivamente quando analisados os aspectos quantitativos do seu desenvolvimento neuropsicomotor e já discutidos anteriormente. Destacase, então, a escola como participante responsável na promoção de um contexto inclusivo, devendo estar apta a receber todos os alunos ${ }^{28}$.

Além disso, ratifica-se a escola e família como responsáveis por proporcionar desenvolvimento nas fases iniciais da vida próximas à vida adulta ${ }^{26}$. No entanto, na abordagem qualitativa, por meio de relato alguns pontos relevantes vieram à tona: mudança no modelo familiar, falta de possibilidades para esporte e lazer, entretenimento por meio de brincadeiras, escola como ambiente predominante, boa autopercepção de saúde, dificuldades de aprendizagem, dificuldade de acessibilidade percebida pelos que têm contato com pessoas com deficiência.

Quanto às relações interpessoais, relacionadas ao modelo familiar e moradia observa-se no presente estudo um panorama atual de modelo de família, o qual não é mais centrado somente na relação pai/mãe ${ }^{29}$. Sabe-se, no entanto, que essas mudanças trazem reflexos para o contexto familiar: o divórcio ou ausência dos pais, número de indivíduos na família, desemprego, baixa escolaridade dos pais, conflitos ou violência são citados como riscos para adversidades no desenvolvimento físico, social, cognitivo e emocional ${ }^{30}$. A ausência de um dos pais foi citada com frequência nas entrevistas, e estudos ${ }^{27}$ apontam que isso pode refletir negativamente nos aspectos social, emocional e cognitivo das crianças e/ou adolescentes.

Embora todos os pré-adolescentes avaliados relatam que têm atividades de lazer e de recreação, a maioria delas foram relacionadas às atividades religiosas, justamente numa fase de desenvolvimento na qual são indicados envolvimento em jogos, atividades lúdicas e até mesmo desportivas ${ }^{31}$. Isso denuncia os fatores contextuais envolvidos, intimamente ligados à situação econômica, a carência de incentivo e de políticas públicas para cultura e esporte no local, num país ainda em desenvolvimento como o Brasil ${ }^{32,33}$.

A dificuldade econômica vem sendo comprovadamente uma barreira para o ótimo desenvolvimento na infância e adolescência ${ }^{30,32}$ o que ratifica a necessidade de estudos tanto transversais como longitudinais com abordagens metodológicas para além dos aspectos quantitativos e físicos do desenvolvimento.

Apenas 2 estudantes relatam que não brincam mais. O brincar, desde muito cedo é o modo de relacionar o mundo para a criança, favorecendo seus processos 
de aprendizagem, aquisição da linguagem, cognição e autoconfiança ${ }^{34}$. Interessante notar que futebol, andar de bicicleta e brincadeiras de ruas foram lembradas pela maioria dos relatos semelhantes a resultados de Nunes e Emmel $^{33}$, na proporção inversa em que as tecnologias foram mencionadas por apenas um aluno como forma de entretenimento. Esses são aspectos positivos que revelam para alguns a prática de esportes e de brincadeiras, o que torna favorável a formação de laços de amizade, além da diversão que proporcionam ${ }^{34} \mathrm{e}$ também podem ser um dos responsáveis pelo bom desempenho psicomotor avaliado.

Nenhum dos pré-adolescentes relatou já trabalhar. Isto aponta para um fator de proteção quanto ao desenvolvimento, uma vez que ocupam seu lugar social mais apropriado que é de estudante, com alguma interface com o brincar, esperado para a idade e relacionado com o desenvolvimento ideal na infância e adolescência ${ }^{35}$.

A maioria tem o ambiente escolar como referência para seus processos de aprendizagem ao considerar que as atividades extra escolares foram pouco mencionadas. A relevância desse dado está no fato da escola ser um ambiente modificável, com influências marcantes no desenvolvimento dos escolares, podendo influenciar até mesmo na sua percepção de bem estar ${ }^{36}$.

Quando questionados sobre sua aprendizagem, 6 alunos afirmam ter dificuldade, tendo como base seu desempenho escolar. As notas de cada disciplina buscam refletir o aprendizado, e para Costa, Lima e Pinheiro ${ }^{37}$, além das questões neurológicas, a aprendizagem na adolescência torna-se mais complexa pelo interesse e relação professor-aluno.

O aluno que relatou dificuldade em escrever está em inclusão. As funções práxicas finas, que englobam a escrita, assim como outras tarefas de manipulação podem apresentar déficits, pela dificuldade de funções refinadas sensório-motora e cognitiva ${ }^{37}$. As crianças com algum déficit de aprendizagem podem necessitar de um maior período de tempo e tentativas para desempenhar e aprender $\operatorname{tarefas}^{34}$.

Em relação aos problemas de saúde mencionados, apenas 3 apresentam repercussões funcionais no cotidiano, sendo a maioria relacionados a alterações alérgicas que podem ter correlação com fatores ambientais não mensurados no presente estudo.

\section{CONCLUSÃO}

Os pré-adolescentes avaliados apresentaram um desenvolvimento neuropsicomotor esperado para a idade em termos quantitativos e qualitativos. A abordagem proposta permitiu identificar dificuldades de um caso específico, relacionado à deficiência intelectual, mas que provavelmente por estar em processo de inclusão apresentou desempenho próximo para sua idade cronológica.

Alguns pontos devem ser destacados nessa faixa etária pelo auto-relato: mudança no modelo familiar, falta de possibilidades para esporte e lazer, entretenimento por meio de brincadeiras, escola como ambiente predominante, boa auto percepção de saúde, dificuldade de acessibilidade percebida pelos que têm contato com pessoas com deficiência.

O panorama multidimensional que compõe a saúde ampliada do pré-adolescente deve ser acompanhado por profissionais e pode ser classificado/ padronizado como dados epidemiológicos relevantes. A $\mathrm{CIF}^{9,10}$ traz esta proposta de observar o contexto ampliado de saúde e cada vez mais utilizado em estudos científicos no Brasil ${ }^{38}$.

O desafio de profissionais e de políticas públicas é implementar seu uso nas mais diversas ações em saúde, como no acompanhamento de crianças, adolescentes e jovens hígidos frequentadores de escolas públicas. 


\section{APÊNDICE 1. ENTREVISTA SEMI-ESTRUTURADA}

\section{Avaliação}

Escola:

Nome:

Data de nascimento: .... /.... / ......

Mora com:

Tem algum problema relacionado a saúde?

Você acredita que sua condição de saúde está interferindo nas suas atividades?

d820 Educação escolar / d815 Educação pré-escolar

Em que série você está estudando? Frequenta escola desde que idade? Deixou de ir à escola algum ano (depois de iniciar os estudos, se sim, por quê?)

Como estão suas notas neste semestre?

d816 Vida pré-escolar e atividades relacionadas / d835 Vida escolar e atividades relacionadas Quais outras atividades de educação você tem na sua rotina? (Aula? Reforço?)

d825 Formação profissional

Faz algum curso profissionalizante? (Ou informática? Ou línguas?) Já trabalha ou trabalhou?

d920 Recreação e lazer

Quais são as atividades de lazer que você participa? (Local, contatos, atividade...)

e320 Amigos

Você diria que está bem entrosada na escola quanto a amizades? Tem alguma dificuldade neste aspecto? (Têm algum colega que você não se dá bem? Como você age diante disso?)

d910 Vida comunitária

Quais outras atividades você tem na sua rotina? (Esporte, cursos, atividade religiosa, organizações...)

d880 Envolvimento nas brincadeiras

e540 Relacionados com os transportes

Como você vem até a escola (e a outras atividades da rotina)?

e515 Arquitetura e a construção 


\section{REFERÊNCIAS}

1. Albuquerque KAd, Mancini MC, Drummond AdF, Megale L, Chagas PSdC. Estimulação ambiental e uso do andador infantil por lactentes com desenvolvimento normal. Rev Bras Saúde Matern Infant. 2011;11(2):181-5. http://dx.doi.org/10.1590/ S1519-38292011000200009.

2. Organización Mundial de La Salud (OMS). La salud de los jóvenes: un reto y una esperanza. Genebra; 1995.

3. Brasil. Lei n. 8.069, de 13 de julho de 1990, dispõe sobre Estatuto da Criança e do Adolescente (ECA). Versão atualizada em 2012. Rio de Janeiro: Cedeca RJ; 2012.

4. Gallahue DL, Ozmun JC. Entendendo o desenvolvimento motor: bebês, crianças, adolescentes e adultos. Boston: McGraw-Hill; 2002.

5. Rosa Neto F. Manual de avaliação motora. Porto Alegre: Artmed; 2002.

6. Tolocka RE, Horita KY, de Oliveira CB, Coelho VAC, Santos DCC. Como brincar pode auxiliar no desenvolvimento de crianças pré-escolares. Licere (Belo Horizonte). 2009;12(1):1-21. Disponível em: https://seer. ufmg.br/index.php/licere/article/view/614/501.

7. Gannotti ME, Christy JB, Heathcock JC, Kolobe TH. A path model for evaluating dosing parameters for children with cerebral palsy. Phys Ther. 2014;94(3):411-21. doi: 10.2522/ ptj.20130022.

8. Organização Mundial de Saúde (OMS). CIF: Classificação Internacional de Funcionalidade, Incapacidade e Saúde. São Paulo: EDUSP; 2003.

9. Organização Mundial de Saúde (OMS). CIF: Classificação Internacional de Funcionalidade, Incapacidade e Saúde. São Paulo: EDUSP; 2015.

10. Organização Mundial de Saúde (OMS). CIF Classificação Internacional de Funcionalidade, Incapacidade e Saúde: actividades e participação, factores ambientais, versão experimental traduzida e adaptada, com base na CIF (2003) e ICF-CY (2007). Porto; 2007.

11. Vale M. Classificação Internacional de Funcionalidade (CIF): conceitos, preconceitos e paradigmas. Contributo de um construto para o percurso real em meio natural de vida. Acta Pediatr Port. 2009;40(5):229-36. Disponível em: http://repositorio.chlc.min-saude.pt/ bitstream/10400.17/891/1/Acta\%20Ped\%20Port\%20 2009_40_229.pdf.

12. CastanedaI L, BergmannII A, BahiaI L. A Classificação Internacional de Funcionalidade, Incapacidade e Saúde: uma revisão sistemática de estudos observacionais. Rev Bras Epidemiol. 2014;437:451. http://dx.doi.org/10.1590/18094503201400020012ENG.

13. Marques AP, Peccin MS. Pesquisa em fisioterapia: a prática baseada em evidências e modelos de estudos. Fisioter Pesq. 2005;11(1):43-8. Disponível em: http://www.revistas.usp. br/fpusp/article/viewFile/76382/80092.

14. 14. Fonseca V. Manual de observação psicomotora, significação psiconeurológica dos fatores psicomotores. Porto Alegre: Artes Médicas; 1995.

15. Riberto M, Miyazaki MH, Jorge Filho D, Sakamoto H, Battistella LR. Reprodutibilidade da versão brasileira da Medida de Independência Funcional. Acta Fisiátr. 2001;8(1):45-52.

16. Minayo MCdS. Análise qualitativa: teoria, passos e fidedignidade qualitative analysis: theory, steps and reliability. Ciên Saúde Coletiva. 2012;17(3):621-6. http:// dx.doi.org/10.1590/S1413-81232012000300007.

17. Campos AC, Silva LH, Pereira K, Rocha NAC, Tudella E. Intervenção psicomotora em crianças de nível socioeconômico baixo. Fisioter Pesq. 2008;15(2):188-93. http://dx.doi.org/10.1590/S1809-29502008000200013.

18. Castilho-Weinert LV, Forti-Bellani CD, editores. Fisioterapia em neuropediatria. Curitiba: Omnipax Editora; 2011. Disponível em: http://omnipax.com.br/livros/2011/ FNP/FNP-livro.pdf.

19. Sanches-Ferreira M, Lopes-dos-Santos P, Santos MA. A desconstrução do conceito de Deficiência Mental e a construção do conceito de Incapacidade Intelectual: de uma perspetiva estática a uma perspetiva dinâmica da funcionalidade. Rev Bras Educ Espec. 2012;18(4):553-68. http://dx.doi.org/10.1590/S1413-65382012000400002.

20. Valentini NC, Coutinho MTC, Pansera SM, Santos Vd, Vieira JLL, Ramalho MH, et al. Prevalência de déficits motores e desordem coordenativa desenvolvimental em crianças da região Sul do Brasil. Rev Paul Pediatr. 2012;30(3):377-84. http://dx.doi.org/10.1590/S0103-05822012000300011.

21. Fonseca Vd. Psicomotricidade e psiconeurologia: introdução ao sistema psicomotor humano (SPMH). Rev Neuropsiq Infância Adolesc. 1994;2(3):23-33. Disponível em: http://www.psiquiatriainfantil.com.br/revista/edicoes/ Ed_02_3/in_05_07.pdf.

22. Kolyniak Filho C. Motricidade e aprendizagem: algumas implicações para a educação escolar. Constr Psicopedag. 2010;18(17):53-66. Disponível em: http://pepsic.bvsalud.org/scielo.php?script $=$ sci arttext\&pid=S1415-69542010000200005.

23. Mansur SS, Marcon AJ. Perfil motor de crianças e adolescentes com deficiência mental moderada. Rev 
Bras Crescimento Desenvolv Hum. 2006;16(3):9-15. Disponível em: http://pepsic.bvsalud.org/pdf/rbcdh/ v16n3/03.pdf.

24. Bezerra GF, Araujo DAdC. Breve estudo sobre a deficiência mental e sua relação com a escola regular: um pouco além das pedras e negativas. In: Anais do $7^{\circ}$ ENIC. 2009;1(1):118. Disponível em: http://anaisonline.uems.br/index.php/ enic/article/view/995.

25. Moura TCd, Santos LHCd, Bruck I, Camargo RMR, Oliver $\mathrm{KA}$, Zonta MB. Independência funcional em indivíduos com paralisia cerebral associada à deficiência intelectual. Rev Pan-Amaz Saúde. 2012;3(1):25-32. doi: 10.5123/ S2176-62232012000100004.

26. Biasoli-Alves ZMM. Orientação de pais: partilhar conhecimentos sobre desenvolvimento e práticas de educação como estratégia de intervenção. Texto Contexto Enferm. 2005;14:64-70. http://dx.doi.org/10.1590/S010407072005000500008.

27. Jaffee SR, Van Hulle C, Rodgers JL. Effects of nonmaternal care in the first 3 years on children's academic skills and behavioral functioning in childhood and early adolescence: a sibling comparison study. Child Dev. 2011;82(4):1076-91. doi: 10.1111/j.1467-8624.2011.01611.x.

28. Silva ACB. Educação inclusiva: contribuições para o desenvolvimento de um compromisso ético em sua efetivação. Rev Ter Ocup Univ São Paulo. 2012;23(2):163-8. http://dx.doi.org/10.11606/issn.2238-6149.v23i2p163-168.

29. Braga MdGR, Amazonas M. Família: maternidade e procriação assistida. Psicol Estud. 2005;10(1):11-8. http:// dx.doi.org/10.1590/S1413-73722005000100003 .

30. Sakuramoto S, Squassoni C, Matsukara T. Social support, parenting style and mental health of childrenand adolescents.
Mundo Saúde. 2014;38(2):169-78. doi: 10.15343/01047809.20143802169178.

31. Gonçalves H, Hallal PC, Amorim TC, Araújo CL, Menezes AM. Fatores socioculturais e nível de atividade física no início da adolescência. Rev Panam Salud Publica. 2007;22(4):246-53. http://dx.doi.org/10.1590/S102049892007000900004.

32. Riechi TIJ, Moura-Ribeiro MVL, Ciasca SM. Impact of preterm birth and low birth weight on the cognition, behavior and learning of school-age children. Rev Paul Pediatr. 2011;29(4):495-501. http://dx.doi.org/10.1590/ S0103-05822011000400005.

33. Nunes AC, Emmel MLG. O uso do tempo nas atividades cotidianas de crianças de classe popular de 9 a 12 anos. Rev Ter Ocup Univ São Paulo. 2015;26(2):176-85.

34. Souza VG, Carvalho AC. A importância do brincar no desenvolvimento psicomotor: relato de experiência. Rev Psicol UNESP. 2011;9(2):79-92.

35. Alberto MdFP, Santos DPd. Trabalho infantil e desenvolvimento: reflexões à luz de Vigotski. Rev Psicol Estudo. 2011;16(20):209-18.

36. Matos MGd, Carvalhosa SF. A saúde dos adolescentes: ambiente escolar e bem-estar. Psicol Saúde Doenças. 2001;2(2):43-53.

37. Costa RPB, Lima MCP, Pinheiro CVdQ. Os impasses da educação na adolescência contemporânea. Bol Psicologia. 2010;60(132):97-106.

38. Ruaro JA, Ruaro MB, Souza DE, Fréz AR, Guerra RO. Panorama e perfil da utilização da CIF no Brasil: uma década de história. Rev Bras Fisioter. 2012;16(6):454-62. 